\title{
Preface: Shallow lakes in a fast changing world
}

\section{The 8th International Shallow Lakes Conference}

\author{
Meryem Beklioğlu • Mariana Meerhoff • \\ Thomas Alexander Davidson • \\ Kemal Ali Ger • Karl E. Havens • Brian Moss
}

Published online: 29 June 2016

(C) Springer International Publishing Switzerland 2016

The 8th International Shallow Lakes Conference was held in Beldibi, Antalya, Turkey, between 12 and 17th October, 2014, and hosted by Limnology Laboratory, Middle East Technical University. Approximately, 295 participants from 37 countries and 6 continents attended the 2014 conference. Previous conferences were held in Silkeborg, Denmark; Mikolajki, Poland; Berlin, Germany; Balatonfured, Hungary; Dalfsen, The Netherlands; Punta Del Este, Uruguay; and Wuxi, China.

Why was this conference important? A very large percentage of the world's lakes are shallow and are fundamentally different from deep lakes. Yet limnology is rooted in research on deep lakes, such that until

B. Moss-passed away during the course of this special volume on 27 May 2016.

Guest editors: M. Beklioğlu, M. Meerhoff, T. A. Davidson, K. A. Ger, K. E. Havens \& B. Moss $\uparrow$ / Shallow Lakes in a Fast Changing World

M. Beklioğlu ( $\square)$

Department of Biological Sciences, Limnology

Laboratory, METU, Ankara, Turkey

e-mail: meryem@metu.edu.tr

M. Meerhoff

CURE-Facultad de Ciencias, Universidad de la

República, Maldonado, Uruguay

T. A. Davidson

Department of Bioscience, Aarhus University, Silkeborg, Denmark recent decades, shallow lakes were less well understood, despite their importance to society and as natural resources. There has been considerable research aimed at better understanding of the dynamics of shallow lakes, to inform more effective management, since the 1980s.

Shallow lakes provide a disproportionate contribution to biodiversity by offering habitat for fish, invertebrates, water fowl, and numerous ecosystem services including significant contributions to global biogeochemical cycles (often carbon sequestration), nutrient cycling, and even food production via aquaculture or artisanal fisheries. These same lakes are uniquely susceptible to disturbance because of their modest depth, which results in them being more responsive to tropical storms, changes in water depth, and other natural and human-based phenomena.

Many shallow lakes occur in lowland areas where there has been intensified land use for (often irrigated)

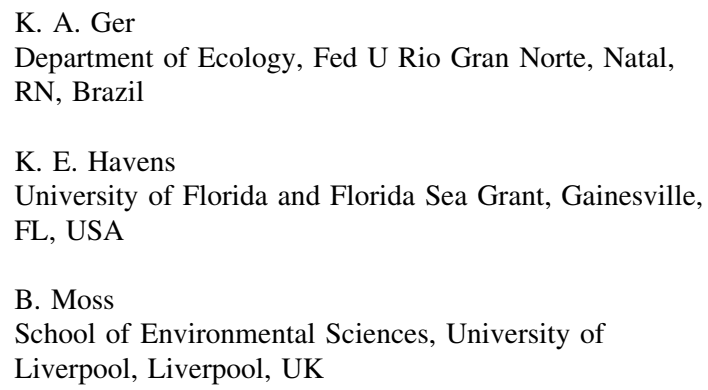


agriculture, residential, and urban development, with trends now occurring worldwide. These uses affect both water quality and quantity of shallow lakes. Shallow lakes are now experiencing simultaneous and synergistic stress from climate change, eutrophication, and other pollution that can lead to a loss of biodiversity, changes in ecosystem function, and a loss of resilience to short-term perturbations, such as changes in rainfall between wet and dry periods and heat waves. The expected increased drought risk in many regions of the world may accelerate ongoing water level reduction in shallow lakes and intensify eutrophication and salinization. The pressure on shallow lakes due to global change is perhaps most dramatic in arid and semi-arid climates. Indeed, many shallow lakes and ponds, such as the large Lake Poopó in Bolivia, are already drying out with a risk of complete loss owing to the combination of a high surface area to depth ratio and future scenarios of drier conditions. Similarly, the third largest freshwater lake in Turkey, Lake Akşehir has completely dried up causing the disappearance or complete extinction of 3 endemic fish species because of diversion of its inflows to the irrigated crop farming.

A major goal and challenge is to understand the responses of shallow lakes to a changing world with many human impacts, but a need to contribute to conservation and mitigation strategies that maintain the structure and function of these ecosystems and their services to society. Disentangling effects of individual (e.g., warming vs. changes in water level vs. eutrophication) and simultaneous stressors are challenging, yet critical to successful management.

The tradition of the Shallow Lakes Conferences is to promote international scientific cooperation by bringing together a relatively small group of scientists to facilitate exchange of ideas. The 2014 conference fostered a friendly yet critical environment for this. A major objective was to identify threats and opportunities for managing shallow lakes in a desired state by providing the scientific underpinnings for lake management.

This special volume of Hydrobiologia contains 19 peer-reviewed, diverse papers that provide new insights. The diverse geographical coverage illustrates the growing network of scientists and emphasizes the diversity of shallow lake ecosystems across the planet. Session topics reflected the recent progress and emerging trends in the field of shallow lake research. Nine plenary lectures dealt with tipping points and resilience in complex ecological systems, effects of trophic structure on metabolism in shallow lakes, integrating ecological and evolutionary responses to environmental change, causes and ecological impacts of water level and salinity changes, landscape limnology, paleoecological perspectives from the past and a view to the future, putting ecology into ecosystem services, and recent advances in the development and use of mathematical models for aquatic ecosystems.

With our deepest sorrow, this special volume also includes an obituary for our dearest Brian Moss who passed away on 27th May 2016. Brian was the true pioneer and inspirational leader of shallow lake ecology but also limnology and ecology at large. He always took an active role for success of shallow lake conferences as well as the proceedings, this one was no exception. He will be truely and deeply missed but his legacy will remain with us.

Both the congress presentations and the articles highlight a diversity of research approaches and foci and reflect the collaborative nature of ongoing shallow lake research. The results emphasize future predictions of increased eutrophication and cyanobacterial blooms, which will be stimulated by increased temperature together with hydrological constraints. Feedbacks between eutrophication and climate change via increased greenhouse gas emissions were also highlighted. Work by congress participants identified promising methods for dealing with adverse effects. Poor communication among academia and relevant stake holders and managers also emerged as a factor preventing or slowing the application of appropriate conservation, restoration, or mitigation measures.

Research aiming to test different current ecological theories using shallow lakes as system models (as occurred with the alternative states hypothesis in the 1990s) or to the development of new theoretical frameworks was also prioritized. Exchange with other academic communities, such as evolutionary ecologists, microbial ecologists, landscape and theoretical ecologists, as well as with investigators in further disciplines, not least economics or anthropology, would also boost our understanding of these complex.

The guest editors thank many reviewers who provided detailed and constructive comments on draft manuscripts, and the authors who responded to those 
reviews in a positive manner that led to a set of valuable research articles on many attributes of shallow lakes.

The next Shallow Lakes Conference will be held in Merida, Cancun, Mexico from 11 to 18th, February
2017, with the theme "Advances in Shallow Lakes' Research." For more information, please contact the general organizers: Dr. S. Nandini (nandini@unam. $\mathrm{mx}$ ) and Prof. S.S.S. Sarma (sarma@unam.mx). 